\title{
Influência de agentes comunitários de saúde na percepção de mulheres e mães sobre conhecimentos de saúde bucal
}

\author{
Influence of community health agents \\ on perception of women and mothers about \\ oral health knowledge
}

Paulo Frazão 1

Débora S. Correia Marques 1

\footnotetext{
1 Programa de PósGraduação em Saúde Coletiva da Unisantos. Rua Dr. Carvalho de Mendonça 144 4 o andar, Vila Mathias, 11070-906, Santos SP. pafrazao@usp.br
}

\begin{abstract}
In 2004, more than 176 thousand Community Health Agents (CHA) were working in Brazil in order to colaborate on health promotion actions and diseases prevention. It has been assumed that their participation through information and knowledge exchange could enable the population to improve their ability to face and fight health problems. The purpose of this study was to describe the effect of their participation on oral health perception in women and mothers (WAM). Social research with before-after design was carried out. The study population consisted of CHA from Rio Grande da Serra County, Sao Paulo State, and a representative sample of WAM. A form with closed questions was applied before and after CHA training to assess perception's changes. The answers were separately analyzed. McNemar test and 5\% significance level was used. The results showed that the differences between $\mathrm{CHA}$ after training were statistically significant $(p<0.05)$ for all fourteen items. Among WAM, statistically significant differences were not observed in only two questions ( $p>0.05)$. Changes on oral health knowledge were noticed, effect that could be attributed to the work of that kind of personnel carried out by home visits.

Keywords Oral health promotion, Community Health Agents, Women and mothers
\end{abstract}

Resumo Em 2004, mais de 176 mil Agentes Comunitários de Saúde (ACS) estavam atuando no Brasil com a finalidade de colaborar nas ações de promoção da saúde e na prevenção das doenças; $e$ de contribuir para fortalecer a capacidade da população no enfrentamento dos problemas de saúde. O propósito deste estudo foi descrever o efeito da atuação dos ACS na percepção de saúde bucal em mulheres e mães (M↔M). Realizou-se uma pesquisa social do tipo antes-depois e a população compreendeu os ACS de Rio Grande da Serra (SP) e uma amostra representativa de $\mathrm{M} \mho M . \mathrm{Pa}-$ ra avaliar a mudança de percepção da população foi aplicado antes e depois da capacitação dos ACS um formulário contendo questões fechadas. As respostas foram analisadas separadamente. Foi empregado o teste do Qui-quadrado de $\mathrm{McNe}$ mar, adotando-se um nível de significância de 5\% para rejeição da hipótese de nulidade. Os resultados mostraram que as diferenças observadas entre os ACS após sua capacitação foram estatisticamente significativas $(p<0,05)$ para todas as 14 questões. Entre as mulheres, não foram observadas diferenças estatisticamente significativas ( $p>0,05)$ em somente duas questões. Foram captadas mudanças nos conhecimentos de saúde bucal apresentados pelas M\&M, efeito que pode ser atribuido ao trabalho desse pessoal, realizado por meio de visitas domiciliares.

Palavras-chave Promoção da saúde bucal, Agentes Comunitários de Saúde, Mulheres e mães 


\section{Introdução}

Desde 1991, o Ministério da Saúde (MS) vem incentivando a inserção de Agentes Comunitários de Saúde (ACS) com a finalidade de colaborar nas ações de promoção da saúde e prevenção das doenças (Brasili1). Em 2004, estavam atuando mais de 176 mil ACS em diferentes comunidades do país. Na região do $\mathrm{ABC}$, formada por sete cidades da área metropolitana da Grande São Paulo, onde vivem mais de dois milhões de cidadãos, mais de 800 agentes estavam atuando em atividades de promoção de saúde.

Em resposta às suas necessidades de capacitação, em 2001 foi realizada uma oficina de 36 horas de duração com ACS que atuavam na região há mais de um ano na função, e idade entre 30 e 45 anos. A finalidade da oficina foi identificar questões de saúde bucal relevantes para eles, agrupá-las em blocos temáticos, discuti-las e cotejá-las com a literatura científica e formular proposições de textos e ilustrações em resposta às questões contidas em cada bloco (Brizolara et al.2). Os resultados revelaram 164 questões, que foram agrupadas em 29 blocos temáticos (Quadro 1). Os textos propostos para abordar as questões geraram a produção do material publicado sob o título "Promovendo a saúde bucal coletiva: manual para agentes comunitários de saúde".

Em 2003, a Secretaria Municipal de Saúde de Rio Grande da Serra (40 mil hab. e gestão plena da atenção básica à saúde), por meio de sua Coordenação de Saúde Bucal, elaborou, como um componente do Programa de Agentes Comunitários de Saúde (PACS), um projeto com o propósito de capacitá-los a lidar com informações sobre problemas comuns de saúde bucal e práticas de autocuidado, entre outros aspectos. Esse projeto - combinando ensinoaprendizagem, apoio e supervisão - foi desenvolvido entre os meses de julho de 2003 a agosto de 2004, empregou como recursos auxiliares o manual mencionado e um filme produzido pelo MS, e teve a duração de 18 horas, distribuídas em 12 horas no 1 o mês, 3 horas no 2 o e no 7 o mês, respectivamente. Durante esse período, os ACS participaram de campanhas de vacinação, dengue, castração canina, entre outros eventos, e treinamentos sobre aspectos relativos à vigilância sanitária e epidemiológica, saúde da criança e da mulher, aleitamento materno, doenças sexualmente transmissíveis, hanseníase, tuberculose.

\section{Quadro 1}

Temas de saúde bucal coletiva segundo a percepção dos ACS. Universidade Metodista de São Paulo, Região do ABC, Área Metropolitana de São Paulo, 2001.

1. O bebê que vai chegar

2. A saúde bucal do bebê até os primeiros dentes

3. Cuidando dos primeiros dentes

4. Os dentes de leite

5. Cárie em dentes de leite em bebês/crianças

6. Como a alimentação pode ajudar na formação da dentição?

7. O normal é ter dentes brancos?

8. O melhor tratamento é a higiene bucal

9. Acidentes com dentes temporários e permanentes

10. Dentes de leite, antibióticos e a consulta odontológica

11. Infecções bucais comuns e o hábito de ranger os dentes

12. A dentição permanente

13. Cor da pele, origem, descendência e as características dos dentes

14. Higiene da dentição permanente

15. Dente do "juízo"

16. Mau hálito

17. Prevenir a gengivite

18. Tratamento de canal

19. Tabaco e álcool

20. Saúde bucal da gestante

21. Adultos e idosos: o flúor ajuda?

22. As doenças do periodonto

23. A boca também envelhece

24. Diabetes, hipertensão e a saúde bucal

25. A dentadura

26. Implantes

27. Práticas comuns quando não se tem acesso à assistência odontológica

28. Participar do desafio da organização de um sistema de saúde para todos

29. Como evitar fatores associados ao câncer bucal

Fonte: Brizolara et al. ${ }^{2}$

Sua ação tem sido dirigida para reforçar o vínculo entre a comunidade e o sistema de saúde, admitindo-se que possa contribuir para maior efetividade das ações de promoção da saúde, prevenção das doenças e assistência individual. Estudos sobre as características do trabalho, os efeitos de sua atuação e o papel desse pessoal, seja como agente institucional, seja como agente da comunidade, foram publicados (Martins et al. ${ }^{3}$, Solla et al.4, Gonzaga \& Müller-Neto ${ }^{5}$, Silva 6 , Nunes et al. ${ }^{7}$, Levy et al. ${ }^{8}$ ). Entretanto, ainda é pequena a documentação existente sobre esse tipo de pessoal nos diferentes âmbitos de sua atuação. Costa et al. ${ }^{9}$ observaram que tanto o Programa Saúde da Família quanto o PACS, que incorporaram a saúde bu- 
cal às suas ações, têm apresentado deficiências na capacitação das equipes, não conseguindo envolver as comunidades atendidas nem avaliar efetivamente as ações de saúde bucal realizadas.

Nas atividades de educação em saúde, admite-se que sua atuação possa, por meio da transmissão de informações e conhecimentos, contribuir para fortalecer a capacidade da população no enfrentamento dos problemas de saúde (Trad \& Bastos $\left.{ }^{10}\right)$. Pesquisa de cunho etnográfico, examinando práticas e discursos, identificou como um aspecto importante da relação dos ACS com o saber médico a necessidade de se analisar o modo como o saber e a prática biomédica, veiculados por intermédio deles, penetra no universo popular (Nunes et al.7).

O propósito deste estudo foi descrever o efeito da atuação dos ACS na percepção de saúde bucal em mulheres e mães residentes na área.

\section{Métodos}

\section{Sujeitos do estudo}

Pesquisa social do tipo antes-depois, empregando entrevista estruturada e dados subjetivos, foi realizada. A SMS contava com 7 dentistas, 3 auxiliares de consultório dentário e 36 ACS, distribuídos em 6 áreas e 5 unidades de saúde da família. Foram obtidos dados do Sistema de Informação da Atenção Básica, relativos à distribuição das características da população cadastrada de três das cinco áreas com unidades de saúde da família (Jardim Santa Tereza, Vila Lopes e Parque América).

A população do estudo compreendeu todos os ACS e uma amostra aleatória de mulheres residindo nas áreas selecionadas. Ambos os sujeitos foram entrevistados antes e após a capacitação em saúde bucal dos primeiros. Mulheres e mães foram selecionadas porque vários autores admitem que elas são cuidadoras primárias nas famílias e têm demonstrado nítida liderança sob adversidades extremas (Kar et al.11).

As famílias eram compostas, em média, de 3,8 membros, sendo que a maioria delas $(86,7 \%)$ tinha até 5 membros. Do total, $98 \%$ moravam em casas de tijolo ou bloco, e 72,5\% residiam em moradias com 3 a 6 cômodos. Quanto às condições de saneamento da população cadastrada, 95,1\% utilizava o serviço de coleta de lixo. O sistema de esgoto, entretanto, atingia $37 \%$ das famílias e $14,8 \%$ faziam uso de fossa séptica, ficando quase metade da população $(48,2 \%)$ sem serviços ou "esgoto a céu aberto". Em relação aos meios de transporte, $47,8 \%$ declararam utilizar ônibus, $10,4 \%$ carro e $19,1 \%$ outros meios. Do total, $94,7 \%$ tinha acesso a rádio ou TV ou ambos. As famílias declararam, em caso de doença, procurar mais a unidade de saúde $(58,9 \%)$ do que o hospital $(28,5 \%)$.

Em relação às mulheres, $29,5 \%$ tinham até 24 anos; $35,7 \%$ de 25 a 39 anos; e $34,8 \%, 40$ anos ou mais. Do total, $93,3 \%$ declararam-se alfabetizadas, e mais de dois terços eram donas de casa $(50,4 \%)$, diaristas $(1,4 \%)$, desempregadas $(5,9 \%)$, estudantes $(10,4 \%)$ e aposentadas $(1,9 \%)$. O restante estava distribuído em mais de duas centenas de categorias de ocupação.

Para manter o controle e evitar que um contexto microssocial e domiciliar excessivamente heterogêneo pudesse confundir os efeitos produzidos pela atuação dos ACS, foram sorteadas mulheres que atravessavam o mesmo ciclo de vida (Wagner et al.12) e pertenciam a famílias de características semelhantes ao universo de famílias assistidas pelo PACS. Assim, foram incluídas no sorteio mulheres de 25 a 39 anos de idade, donas de casa, alfabetizadas, que residiam em domicílios de tijolos ou blocos com 3 a 6 cômodos. Os resultados da aplicação desses critérios de inclusão na determinação da população de referência (Tabela 1) implicaram na seleção de duas áreas: Jardim Santa Tereza e Vila Lopes. Considerando-se a população finita de 398 mulheres, uma freqüência esperada de $25 \%$ nas categorias de resposta das diferentes questões e uma margem de erro de 7,5\%, o tamanho da amostra necessário era 97 sujeitos para um nível de confiança de $95 \%$. Como a esse valor foi aplicada uma taxa de perda de $20 \%$, foram sorteadas 120 mulheres, sendo 60 em cada bairro. Após a identificação da família a qual a mulher sorteada pertencia, e o endereço, a coleta de dados foi programada.

\section{Instrumento de coleta dos dados}

O primeiro passo foi a identificação dos aspectos a serem abordados, de modo a conferir ao conjunto as qualidades desejadas para avaliar os domínios relevantes relacionados ao fenômeno sob estudo. 
Tabela 1

Distribuição percentual da população de referência segundo as áreas selecionadas. Rio Grande da Serra, 2004.

\begin{tabular}{|c|c|c|c|c|c|c|c|c|}
\hline \multirow[t]{2}{*}{ Área } & \multicolumn{2}{|c|}{$\begin{array}{l}\text { Famílias } \\
\text { cadastradas }\end{array}$} & \multicolumn{2}{|c|}{$\begin{array}{l}\text { Domicílios } \\
\text { de } 3 \text { a } 6 \text { cômodos }\end{array}$} & \multicolumn{2}{|c|}{$\begin{array}{l}\text { Mulheres de } 25 \text { a } 39 \text { anos } \\
\text { donas de casa alfabetizadas }\end{array}$} & \multicolumn{2}{|c|}{$\begin{array}{l}\text { População } \\
\text { de referência }\end{array}$} \\
\hline & $\mathbf{n}$ & $\%$ & $\mathbf{n}$ & $\%$ & $\mathbf{n}$ & $\%$ & $\mathbf{n}$ & $\%$ \\
\hline Santa Tereza & 1.416 & 47,4 & 1.095 & 71,7 & 366 & 42,1 & 274 & 68,5 \\
\hline Vila Lopes & 921 & 30,9 & 420 & 27,5 & 284 & 32,7 & 124 & 31,0 \\
\hline Pq. América & 648 & 21,7 & 12 & 0,8 & 219 & 25,2 & 2 & 0,5 \\
\hline Total & 2.985 & 100,0 & 1.527 & 100,0 & 869 & 100,0 & 400 & 100,0 \\
\hline
\end{tabular}

Para a montagem do instrumento, a opção recaiu sobre o emprego do formulário (Vieira \& Hossne13), o qual foi composto de duas partes: na primeira, foram elaboradas questões envolvendo atributos pessoais dos sujeitos em estudo; na segunda, foram dispostas questões sobre a percepção dos sujeitos, estruturadas em três grupos de indicadores para mensurar os seguintes aspectos: (a) ciclos de vida e saúdedoença bucal: 14 itens elaborados para identificar conhecimentos de saúde bucal em diferentes fases e condições de vida - infância, adolescência, vida adulta, terceira idade, gestação; (b) práticas e capacidades auto-referidas: cinco itens abordando o uso de escovas individuais ou coletivas, freqüência de escovação e de uso de fio dental, auto-eficiência sobre limpeza dos dentes e habilidades em auto-exame; e (c) acesso e utilização de serviços odontológicos: dois itens.

Neste artigo são apresentados e discutidos os resultados relativos ao primeiro grupo de indicadores. A elaboração das 14 questões concernentes a conhecimentos de saúde bucal e ciclos de vida teve por base a publicação "Promovendo a saúde bucal coletiva: manual para os agentes comunitários de saúde" (Frazão14), cujo conteúdo foi identificado por ACS, um tipo de pessoal do qual se exige residência na área de atuação. Essa exigência implica em laços com a comunidade a qual pertence. É provável que esse grau de pertencimento traga no seu bojo mais semelhanças do que diferenças socioculturais com a comunidade. A produção do manual foi realizada através dos seguintes passos: (a) levantamento dos problemas de saúde bucal mais comuns na comunidade; (b) formulação de perguntas sobre esses problemas; (c) seleção das questões relevantes para a comunidade a serem incluídas na produção do material educativo; (d) agrupamento das per- guntas afins em blocos temáticos; (e) delineamento da estrutura geral do material; (f) proposição de textos e ilustrações em resposta às questões contidas em cada bloco temático; (g) submissão das proposições à avaliação dos grupos (Brizolara et al.2). Segundo os autores, para incentivar a participação ativa dos ACS foi adotada a técnica de atividade de grupo, na qual o monitor estimula a emergência das diferentes percepções e a problematização; e incentiva a apreciação da evolução do trabalho, de modo a permitir o intercâmbio de experiências e conhecimentos, e propiciar a comunicação multilateral entre os agentes (Bordenave \& Pereira15).

Assim, pode-se admitir que o conteúdo do instrumento, ao ser composto de excertos do manual construído sob as condições mencionadas, conferiu ao primeiro as necessárias propriedades de validade de face e de conteúdo, estabelecendo correspondência entre a sua composição e o que se pretendeu apreciar (Streiner \& Norman 16 , Piovesan \& Temporini17).

Após a definição dos domínios a serem abordados, passou-se à determinação do tipo de escala relativo ao formato de cada item. A opção adotada nesse grupo de indicadores foi pela apresentação na forma de questões de múltipla escolha, em que as perguntas apresentavam categorias de respostas fixas para que o respondente escolhesse a que melhor representasse sua percepção de saúde bucal.

Teorias sobre percepção podem ser encontradas em diversas áreas (sociologia, psicologia social, antropologia, etc.), submetidas a diferentes enfoques. Neste estudo, a percepção é definida como uma experiência ou noção dotada de significação e sentido. Corresponde à expressão de uma forma, entre muitas, de conhecimento e de representação da relação do sujeito com aspectos do mundo percebido, en- 
volvendo rede complexa de relações e campo de valores (Chauí18). Em cada questão correspondente a uma unidade temática, foram reunidas diferentes noções, sendo uma delas embasada no conteúdo do manual elaborado com os ACS e as outras em noções usuais, de modo a conferir ao conjunto de questões um determinado domínio de conhecimentos e informações sobre saúde bucal.

No glossário de promoção da saúde, as habilidades pessoais, cognitivas e sociais - que determinam a aptidão de indivíduos para obter acesso, entender e usar informações a fim de promover e manter boa saúde - vêm sendo denominadas de health literacy (Nutbeam ${ }^{19}$ ), uma expressão em língua inglesa que pode ser traduzida por formação em ou domínio sobre informações e conhecimentos de saúde. Admite-se que o domínio sobre informações de saúde pode resultar em melhor compreensão dos determinantes de saúde, pode provocar mudanças de atitudes e motivações sobre comportamentos de saúde, elevando a autosuficiência em relação a tarefas definidas.

$\mathrm{Na}$ formulação das questões, foram evitadas respostas sintéticas dicotômicas do tipo "sim" e "não", "verdadeiro" ou "falso" e "certo" ou "errado" (Richardson 20 ); formulação textual com respostas do tipo "sempre" e "nunca"; questões ou itens longos, com mais de uma idéia embutida, que poderiam gerar ambigüidade de interpretação tanto nas perguntas quanto nas respostas. Procurou-se garantir que as alternativas fossem mutuamente exclusivas e que, qualquer que fosse a situação do respondente, houvesse uma opção de resposta. Assim, em todas as questões a opção "não sabe, não respondeu" foi oferecida. As alternativas esperadas foram distribuídas em diferentes posições, evitando-se possíveis tendências em sua escolha.

Pretendeu-se que essas opções de resposta funcionassem como indicadores capazes de medir os efeitos da atuação dos ACS no domínio de conhecimentos e informações de saúde bucal dos moradores. Foi realizado um pré-teste em sujeitos portadores de características semelhantes às da população-alvo. Algumas questões foram reelaboradas para adequar o instrumento ao vocabulário dos respondentes (Piovesan \& Temporini17). O tempo variou entre 20 e 30 minutos, e atendeu, portanto, a necessidade de não provocar sobrecarga no informante (Goode \& Hatt ${ }^{21}$ ).

\section{Coleta e análise dos dados}

Aprovado pelo Comitê de Ética em Pesquisa do Hospital Guilherme Álvaro da Secretaria de Estado da Saúde de São Paulo, o formulário foi aplicado em julho de 2003 e julho de 2004. Diferenças nas características de escolaridade e renda foram determinadas pelo teste do Quiquadrado de Pearson. Para analisar as questões sobre saúde bucal e ciclos de vida, representadas por escalas nominais, foi adotada a interpretação clássica com foco na probabilidade de ocorrência das diferentes categorias em cada questão (Pereira22). Como nessas questões o sentido de direção é dado apenas por uma das categorias da escala, em cada grupo (ACS e mulheres) e para cada questão, a proporção de respostas na categoria de conhecimento esperada foi comparada em relação à proporção representada pelas demais categorias, com base na sua probabilidade de ocorrência numa distribuição binomial. As diferenças entre as proporções foram analisadas empregando-se o teste do Qui-quadrado de McNemar, considerando-se para rejeição da hipótese de nulidade um nível de significância de 5\%. O aplicativo Statistical Package for Social Sciences 11.02001 (SPSS Inc. Headquarters, Chicago, Illinois, EUA) foi empregado.

\section{Resultados}

Permaneceram no estudo 32 agentes comunitários e 91 moradoras, sendo excluídas da base de dados as observações que não se repetiram. Não responderam à segunda observação 4 ACS, porque foram desligados do programa, e 29 donas de casa, por motivos diversos (mudança de endereço, hospitalização, falecimento de uma entrevistada, entre outros). A maioria $(86,8 \%)$ das donas de casa tinha filhos.

No gráfico 1, é mostrada a distribuição da população do estudo segundo o grau de escolaridade. A maioria dos ACS apresentava curso secundário concluído. Entre as mulheres donas de casa, a escolaridade variava bastante. Enquanto $1 / 3$ não havia concluído o 1 o grau, 1/3 possuía o curso secundário completo. Diferenças significativas foram identificadas na distribuição da escolaridade entre as duas populações $(p=0,000)$.

Quanto à renda familiar, valores superiores $(\mathrm{p}=0,064)$ para os ACS em relação às mulheres foram observados (Gráfico 2). Quanto ao 
Gráfico 1

Distribuição da população do estudo segundo a escolaridade. Rio Grande da Serra, 2004.

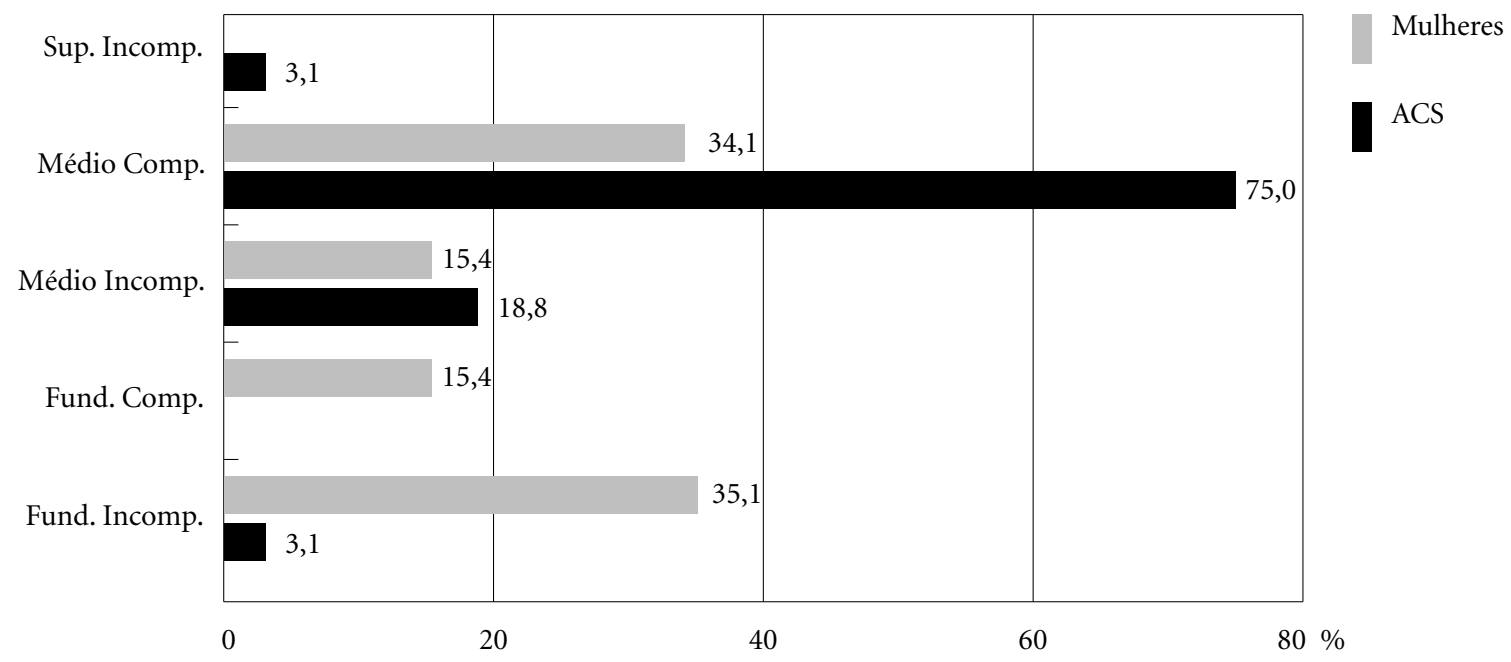

$\chi 2=25,87 \mathrm{p}=0,000$

Gráfico 2

Distribuição percentual da população do estudo segundo renda familiar mensal declarada. Rio Grande da Serra, 2004.

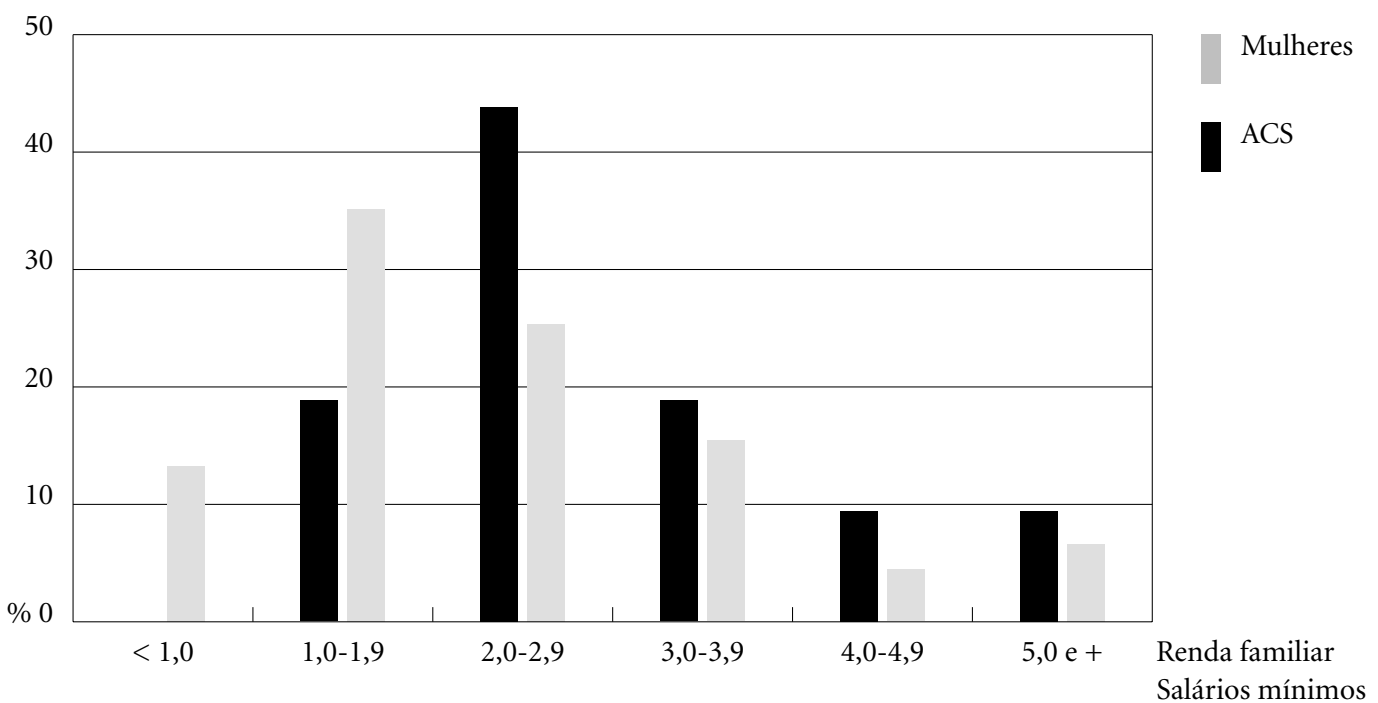


tempo de residência no bairro, a maioria dos ACS $(93,7 \%)$ e das mulheres $(83,5 \%)$ morava na área há pelo menos cinco anos.

A distribuição percentual das categorias de respostas relativas às questões, antes e depois da capacitação dos ACS, é apresentada na tabela 2. Na segunda coluna, são mostrados os valores relativos observados entre os ACS, enquanto na terceira coluna, as proporções correspondentes às mulheres.

Em relação aos conhecimentos de saúde bucal e ciclo de vida, 14 questões foram formuladas, das quais três apresentaram na primeira observação elevadas taxas de resposta espera$\mathrm{da}$, tanto entre os ACS quanto entre as mulheres. Por essa razão, esses itens foram considerados indicadores fracos para avaliar mudanças na percepção dos sujeitos do estudo. Por outro lado, revelaram que ambos os sujeitos percebe- ram, como causa de uma dentição forte, a importância dos cuidados com a higiene bucal e a alimentação, desprezando categorias que faziam menção à herança dos pais, "raça" e condição financeira da pessoa. Em relação a alternativas que podem levar o dente a precisar de tratamento de canal, a maioria dos respondentes indicou a opção esperada (lesão de cárie não tratada). Além disso, na população do estudo, a importância do uso do flúor em todas as fases da vida, e não apenas na infância, na época de formação e erupção dos dentes, foi amplamente reconhecida.

Analisando-se as questões separadamente, pode-se observar que as taxas de respostas esperadas, entre os 32 ACS, foram mais elevadas, doze meses depois de sua capacitação, em comparação com os valores aferidos previamente ao treinamento. Das 14 questões incluídas na

Tabela 2

Distribuição da população do estudo segundo as respostas relativas a cada questão. Rio Grande da Serra, 2004.

\begin{tabular}{|c|c|c|c|c|c|c|c|c|}
\hline & \multicolumn{4}{|c|}{ ACS } & \multicolumn{4}{|c|}{ Mulheres } \\
\hline & \multicolumn{2}{|c|}{ antes } & \multicolumn{2}{|c|}{ depois } & \multicolumn{2}{|c|}{ antes } & \multicolumn{2}{|c|}{ depois } \\
\hline & $\mathbf{n}$ & $\%$ & $\mathbf{n}$ & $\%$ & $\mathbf{n}$ & $\%$ & $\mathbf{n}$ & $\%$ \\
\hline \multicolumn{9}{|l|}{$\begin{array}{l}\text { Quanto à higiene bucal } \\
\text { do recém-nascido, é correto: }\end{array}$} \\
\hline Usar somente escova dental & - & - & - & - & 1 & 1,1 & - & - \\
\hline Usar escova e pasta de dentes com flúor & - & - & - & - & 2 & 2,2 & 1 & 1,1 \\
\hline Usar gaze ou fralda umedecida em água limpa & 27 & 84,4 & 32 & 100,0 & 61 & 67,0 & 87 & 95,6 \\
\hline $\begin{array}{l}\text { Por ser bebê e ainda não ter dentes, } \\
\text { não é necessário limpar a boca }\end{array}$ & - & - & - & - & 8 & 8,8 & 3 & 3,3 \\
\hline Somente o dentista deve limpar a boca do bebê & - & - & - & - & 3 & 3,3 & - & - \\
\hline Não sabe/não informou & 5 & 15,6 & - & - & 16 & 17,6 & - & - \\
\hline \multicolumn{9}{|l|}{$\begin{array}{l}\text { Na sua percepção, em relação } \\
\text { aos dentes de leite, a opção correta é: }\end{array}$} \\
\hline $\begin{array}{l}\text { Por serem dentes temporários, } \\
\text { não necessitam de cuidados }\end{array}$ & - & - & - & - & 6 & 6,6 & - & - \\
\hline $\begin{array}{l}\text { Guiam a erupção ou o "nascimento" } \\
\text { dos dentes permanentes }\end{array}$ & 20 & 62,5 & 30 & 93,8 & 29 & 31,9 & 57 & 62,6 \\
\hline $\begin{array}{l}\text { Surgem na boca quando a mãe pára } \\
\text { de amamentar o bebê }\end{array}$ & - & - & - & - & 3 & 3,3 & - & - \\
\hline $\begin{array}{l}\text { São dentes que caem facilmente } \\
\text { porque não têm raízes }\end{array}$ & 12 & 37,5 & 2 & 6,3 & 32 & 35,2 & 32 & 35,2 \\
\hline Não sabe/não informou & - & - & - & - & 21 & 23,1 & 2 & 2,2 \\
\hline \multicolumn{9}{|l|}{$\begin{array}{l}\text { Do nascimento até a idade adulta, } \\
\text { quantas são as trocas de dentes? }\end{array}$} \\
\hline Uma & 14 & 43,8 & 29 & 90,6 & 45 & 49,5 & 74 & 81,3 \\
\hline Duas & 11 & 34,4 & 3 & 9,4 & 36 & 39,6 & 16 & 17,6 \\
\hline Três, incluindo o dente do siso (3o molar) & 6 & 18,8 & - & - & 9 & 9,9 & - & - \\
\hline Não sabe/ não informou & 1 & 3,1 & - & & 1 & 1,1 & 1 & 1,1 \\
\hline
\end{tabular}

(continua) 


\begin{tabular}{|c|c|c|c|c|c|c|c|c|}
\hline & \multicolumn{4}{|c|}{ ACS } & \multicolumn{4}{|c|}{ Mulheres } \\
\hline & \multicolumn{2}{|c|}{ antes } & \multicolumn{2}{|c|}{ depois } & \multicolumn{2}{|c|}{ antes } & \multicolumn{2}{|c|}{ depois } \\
\hline & $\mathbf{n}$ & $\%$ & $\mathbf{n}$ & $\%$ & $\mathbf{n}$ & $\%$ & $\mathbf{n}$ & $\%$ \\
\hline \multirow{2}{*}{\multicolumn{9}{|c|}{$\begin{array}{l}\text { Em que idade começam a nascer } \\
\text { os primeiros dentes permanentes? }\end{array}$}} \\
\hline & & & & & & & & \\
\hline Por volta de 6 meses a 1 ano & 5 & 15,6 & - & - & 16 & 17,6 & - & - \\
\hline De 2 a 3 anos & 1 & 3,1 & - & - & 5 & 5,5 & 1 & 1,1 \\
\hline De 5 a 6 anos & 14 & 43,8 & 28 & 87,5 & 40 & 44,0 & 66 & 72,5 \\
\hline De 8 a 9 anos & 12 & 37,5 & 4 & 12,5 & 26 & 28,6 & 24 & 26,4 \\
\hline De 11 a 12 anos & - & - & - & - & 4 & 4,4 & - & - \\
\hline \multicolumn{9}{|l|}{ Algumas pessoas possuem dentição } \\
\hline \multicolumn{9}{|l|}{ forte devido a: } \\
\hline Herança dos pais (nascença) & 2 & 6,3 & - & - & 5 & 5,5 & 1 & 1,1 \\
\hline Tipos de raça & - & - & - & - & 3 & 3,3 & - & - \\
\hline Boa condição financeira & - & - & - & - & 5 & 5,5 & - & - \\
\hline Cuidados com a higiene bucal e alimentação & 30 & 93,8 & 32 & 100,0 & 75 & 82,4 & 90 & 98,9 \\
\hline Não sabe/não informou & - & - & - & - & 3 & 3,3 & - & - \\
\hline \multicolumn{9}{|l|}{ A cárie é provocada principalmente por: } \\
\hline Má formação da estrutura dos dentes & - & - & - & - & 3 & 3,3 & - & - \\
\hline Bactérias aderidas aos dentes & 16 & 50,0 & 2 & 6,3 & 19 & 20,9 & 1 & 1,1 \\
\hline Uso constante de antibióticos & 3 & 9,4 & 1 & 3,1 & 8 & 8,8 & 1 & 1,1 \\
\hline Falta de saliva na boca & - & - & - & - & - & - & - & - \\
\hline Ingestão freqüente de produtos açucarados & 13 & 40,6 & 29 & 90,6 & 57 & 62,6 & 89 & 97,8 \\
\hline Não sabe/não informou & - & - & - & - & 4 & 4,4 & - & - \\
\hline \multicolumn{9}{|l|}{ Mau hálito é causado por: } \\
\hline Estresse emocional & 1 & 3,1 & - & - & 1 & 1,1 & - & - \\
\hline Uso de medicamentos & - & - & - & - & - & - & - & - \\
\hline Fumo e álcool em excesso & 3 & 9,4 & 1 & 3,1 & 22 & 24,2 & 14 & 15,4 \\
\hline $\begin{array}{l}\text { Falta de remoção da placa bacteriana } \\
\text { que se acumula nos dentes e na língua }\end{array}$ & 25 & 78,1 & 31 & 96,9 & 48 & 52,7 & 70 & 76,9 \\
\hline Alimentos açucarados e gordurosos & 3 & 9,4 & - & - & 6 & 6,6 & 2 & 2,2 \\
\hline Não sabe/não informou & - & - & - & - & 14 & 15,4 & 5 & 5,5 \\
\hline \multicolumn{9}{|l|}{ O sangramento da gengiva é: } \\
\hline Normal e sempre ocorre com a escovação & 1 & 3,1 & - & - & 8 & 8,8 & 2 & 2,2 \\
\hline O maior causador da cárie dental & 1 & 3,1 & 1 & 3,1 & 1 & 1,1 & - & - \\
\hline Uma infecção que atinge o nervo do dente & 5 & 15,6 & - & - & 13 & 14,3 & 3 & 3,3 \\
\hline O primeiro sinal de uma doença gengival & 23 & 71,9 & 31 & 96,9 & 53 & 58,2 & 79 & 86,8 \\
\hline Não sabe/não informou & 2 & 6,3 & - & - & 16 & 17,6 & 7 & 7,7 \\
\hline \multicolumn{9}{|c|}{$\begin{array}{l}\text { Para evitar a inflamação da gengiva, é preciso realizar } \\
\text { procedimentos de higiene bucal, utilizando corretamente: }\end{array}$} \\
\hline Apenas escova dental & - & - & - & - & - & - & - & - \\
\hline Escova dental e pastas com flúor & 10 & 31,3 & 3 & 9,4 & 10 & 11,0 & 8 & 8,8 \\
\hline Escova e fio dental & 13 & 40,6 & 28 & 87,5 & 20 & 22,0 & 35 & 38,5 \\
\hline $\begin{array}{l}\text { Líquidos especiais para bochechos } \\
\text { e soluções de flúor }\end{array}$ & 9 & 28,1 & 1 & 3,1 & 53 & 58,2 & 48 & 52,7 \\
\hline Não sabe/não informou & - & - & - & - & 8 & 8,8 & - & - \\
\hline \multicolumn{9}{|l|}{$\begin{array}{l}\text { Indique a opção que pode levar o dente } \\
\text { a precisar de tratamento de canal: }\end{array}$} \\
\hline Lesão de cárie não tratada & 29 & 90,6 & 32 & 100,0 & 75 & 82,4 & 86 & 94,5 \\
\hline Excesso de flúor & - & - & - & - & - & - & - & - \\
\hline Uso de dentadura quebrada & - & - & - & - & 2 & 2,2 & - & - \\
\hline Ponte móvel mal adaptada & - & - & - & - & 1 & 1,1 & - & - \\
\hline Não sabe/não informou & 3 & 9,4 & - & - & 13 & 14,3 & 5 & 5,5 \\
\hline
\end{tabular}

(continua) 


\begin{tabular}{|c|c|c|c|c|c|c|c|c|}
\hline & \multicolumn{4}{|c|}{ ACS } & \multicolumn{4}{|c|}{ Mulheres } \\
\hline & \multicolumn{2}{|c|}{ antes } & \multicolumn{2}{|c|}{ depois } & \multicolumn{2}{|c|}{ antes } & \multicolumn{2}{|c|}{ depois } \\
\hline & $\mathbf{N}$ & $\%$ & $\mathbf{N}$ & $\%$ & $\mathbf{n}$ & $\%$ & $\mathbf{n}$ & $\%$ \\
\hline \multicolumn{9}{|l|}{$\begin{array}{l}\text { Durante a gravidez, o aumento } \\
\text { do número de cáries se deve a: }\end{array}$} \\
\hline Enfraquecimento dos dentes pela perda de cálcio & 17 & 53,1 & 9 & 28,1 & 52 & 57,1 & 51 & 56,0 \\
\hline Maior consumo de produtos açucarados & 2 & 6,3 & 19 & 59,4 & 5 & 5,5 & 22 & 24,2 \\
\hline Alterações hormonais & 9 & 28,1 & 4 & 12,5 & 4 & 4,4 & 2 & 2,2 \\
\hline Medicamentos (ex: antibióticos) & - & - & - & - & 15 & 16,5 & 12 & 13,2 \\
\hline Não sabe/não informou & 4 & 12,5 & - & - & 15 & 16,5 & 4 & 4,4 \\
\hline \multicolumn{9}{|l|}{$\begin{array}{l}\text { Durante a gravidez, você acha } \\
\text { que o tratamento dentário deve ser? }\end{array}$} \\
\hline Preventivo e periódico & 27 & 84,4 & 31 & 96,9 & 51 & 56,0 & 69 & 75,8 \\
\hline Evitado durante toda a gestação & 2 & 6,3 & - & - & 10 & 11,0 & 3 & 3,3 \\
\hline Para os casos de urgência & 2 & 6,3 & 1 & 3,1 & 16 & 17,6 & 18 & 19,8 \\
\hline Para a gestante que não utiliza água fluoretada & 1 & 3,1 & - & - & 3 & 3,3 & 1 & 1,1 \\
\hline Não sabe/não informou & - & - & - & - & 11 & 12,1 & - & - \\
\hline \multicolumn{9}{|l|}{ O flúor é importante: } \\
\hline $\begin{array}{l}\text { Apenas na infância, na época } \\
\text { de formação e erupção dos dentes }\end{array}$ & 1 & 3,1 & - & - & 12 & 13,2 & 2 & 2,2 \\
\hline Na vida adulta & - & - & - & - & - & - & - & - \\
\hline Na terceira idade & - & - & - & - & 1 & 1,1 & - & - \\
\hline Em todas as fases da vida & 31 & 96,9 & 32 & 100,0 & 73 & 80,2 & 89 & 97,8 \\
\hline Não sabe/ não informou & - & - & - & - & 5 & 5,5 & - & - \\
\hline \multicolumn{9}{|l|}{$\begin{array}{l}\text { Indique o fator de risco mais relacionado } \\
\text { ao aparecimento do câncer bucal: }\end{array}$} \\
\hline Ingestão de medicamentos & - & - & - & - & 2 & 2,2 & - & - \\
\hline Alimentação rica em sal e açúcar & - & - & - & & 2 & 2,2 & 1 & 1,1 \\
\hline Excesso de álcool e fumo & 21 & 65,6 & 31 & 96,9 & 59 & 64,8 & 82 & 90,1 \\
\hline Perda dos dentes permanentes & 2 & 6,3 & 1 & 3,1 & 7 & 7,7 & 4 & 4,4 \\
\hline Não sabe/não informou & 9 & 28,1 & - & - & 21 & 23,1 & 4 & 4,4 \\
\hline
\end{tabular}

tabela 2, três apresentaram taxas acima de 75\% na primeira observação. Elas versavam sobre higiene bucal do recém-nascido, mau hálito e assistência individual durante a gravidez. Embora elas possam ser consideradas indicadores fracos para a detecção de mudanças em nível cognitivo, essas questões podem ser recursos rápidos e simples para identificar ACS com severas insuficiências em termos de conhecimentos básicos de saúde bucal.

$\mathrm{Na}$ amostra de mulheres, as taxas de respostas esperadas também mostraram elevação entre a primeira e a segunda observação em todas as questões. A menor elevação, de 22,0 para $38,5 \%$ - equivalente ao incremento de $16,5 \%$-, ocorreu no item relativo à prevenção da inflamação gengival.

Comparando-se os valores observados entre os ACS e as mulheres na primeira observa- ção, algumas diferenças podem ser destacadas. De modo geral, entre as mulheres, as freqüências relativas distribuíram-se mais variadamente entre as categorias de resposta, e os valores relativos à categoria correspondente à alternativa esperada foram inferiores. Isso não ocorreu em quatro questões, em que a dispersão entre as categorias de resposta foi semelhante para ambos os grupos. Os itens que apresentaram conhecimentos equivalentes entre os dois grupos versavam sobre o número de trocas dentárias, a faixa etária na qual os primeiros dentes permanentes erupcionam, condições que provocam lesões de cárie e fatores de risco para câncer bucal (Tabela 2).

Considerando-se a categoria esperada de conhecimento específico, os resultados apresentados na tabela 3 mostraram que as diferenças observadas entre os ACS após sua capacitação 
foram estatisticamente significativas $(\mathrm{p}<0,05)$ para todas as 14 questões. Entre as mulheres, não foram observadas diferenças estatisticamente significativas $(\mathrm{p}>0,05)$ em duas questões. Enquanto uma delas dizia respeito aos dentes de leite, em que uma proporção importante da amostra de mulheres $(37,4 \%)$, após a segunda observação, não considerou que eram elementos importantes para guiar a erupção dos dentes permanentes; a outra fazia referência à idade de surgimento dos primeiros dentes permanentes, em que uma taxa relevante de mulheres $(27,5 \%)$ não indicou o período de 5 a 6 anos de idade.

Em outras duas questões, embora as diferenças antes e após a capacitação dos ACS, em ambas as populações, sejam estatisticamente significativas, os valores obtidos mostraram claras dificuldades de assimilação pelos ACS do saber odontológico especificamente implicado nessa questão, com conseqüências nítidas para a distribuição das respostas representativas do universo de percepções das mulheres (Tabela 3 ). Essas questões tratavam de procedimentos para evitar a inflamação gengival e o papel do consumo de produtos açucarados no aumento do número de lesões de cárie na gravidez.

\section{Discussão}

Mudanças de conhecimentos foram avaliadas na população dos ACS e numa amostra representativa de mulheres, por meio da aplicação de um formulário contendo perguntas fechadas, construído com base no conteúdo da capacitação e especialmente elaborado para esse fim.

Embora perguntas fechadas sejam fáceis de codificar e o pesquisador possa transferir as informações para o computador sem maiores problemas, a questão fechada mal formulada pode conter ambigüidades. Nessa situação, os sujeitos podem divergir sobre o entendimento da questão. Ainda que tenham respondido ao mesmo item, os sujeitos podem ter emitido respostas sobre diferentes temas. Para Lefèvre $^{23}$, na pesquisa social, a questão da ambigüidade, quase sempre, está presente nas perguntas dos pesquisadores e nas respostas dos pesquisados. O autor afirma que somente questões abertas permitem ao sujeito respostas discursivas nas quais, a partir de [...] quantidades maiores de material verbal é possível, em princípio, saber com mais objetividade e certe$z a$ (ou com menos ambigüidade) aquilo que efe- tivamente os indivíduos pensam a respeito de um dado tema.

De fato, na pesquisa social, a opção por questões abertas ou fechadas, ou ambas, encerra um rol de implicações teóricas e metodológicas cuja discussão ultrapassa, obviamente, os propósitos deste artigo. Questões abertas também podem conter ambigüidades. Além disso, exigem muito maior esforço e tempo durante a coleta dos dados, somado ao fato de que a categorização e análise das respostas dependem mais intensamente de uma série de qualidades do pesquisador, entre as quais, intuição, história de vida, inteligência, capital cultural. A adoção por um ou outro tipo deve considerar os diferentes aspectos da investigação que será realizada. A opção pela construção de um instrumento contendo, entre outros tipos de questão, perguntas fechadas, permitiu à pesquisadora um número maior de observações, maior uniformidade na interpretação dos dados e dos critérios adotados, conferindo controle apropriado da aplicação nos dois momentos previstos, isto é, antes e depois da atuação dos ACS. Além disso, itens de múltipla escolha (número máximo de cinco), em que uma alternativa é esperada, são mais fáceis de corrigir e analisar em termos de padrões de respostas incorretas do que outras formas (Richardson $^{20}$ ). A entrevistadora não precisou escrever; apenas marcou a alternativa que melhor se aplicava; o que facilitou o preenchimento do formulário e a coleta dos dados junto às mulheres das duas áreas selecionadas.

Instrumentos contendo perguntas fechadas têm sido empregados em diferentes estudos para avaliar conhecimentos (Valentini et al.24, Flores \& Drehmer25, Faustini et al.26). No que pesem esses aspectos, o estudo teve algumas limitações. Não foi possível estabelecer uma amostra de mulheres que pudesse servir de grupo de controle para comparar as mudanças na amostra de mulheres cadastradas na área de atuação dos ACS. As atividades voltadas à saúde bucal dos ACS, durante o período do estudo, não foram isoladas das demais atividades de treinamento e de visitas domiciliares por eles realizadas. Outros recursos, como por exemplo, informações sobre saúde eventualmente veiculadas por meios de comunicação de massa $(94,7 \%$ da população de referência tinha acesso a radio ou TV ou ambos) não foram registradas.

A despeito dessas limitações, alguns aspectos podem ser destacados com base nos resul- 
Tabela 3

Distribuição da população do estudo segundo a categoria de conhecimento esperada em cada questão. Rio Grande da Serra, 2004.

\begin{tabular}{|c|c|c|c|c|c|c|}
\hline & & ACS & & & Mulhere & \\
\hline & $\begin{array}{c}\text { antes } \\
\%\end{array}$ & $\begin{array}{l}\text { depois } \\
\%\end{array}$ & $\begin{array}{l}\text { valor } \\
\text { "p" }\end{array}$ & $\begin{array}{c}\text { antes } \\
\%\end{array}$ & $\begin{array}{l}\text { depois } \\
\quad \%\end{array}$ & $\begin{array}{l}\text { valor } \\
\text { "p" }\end{array}$ \\
\hline $\begin{array}{l}\text { Quanto à higiene bucal } \\
\text { do recém-nascido, é correto: }\end{array}$ & & & & & & \\
\hline Demais categorias & 15,6 & - & & 33,0 & 4,4 & \\
\hline Usar gaze ou fralda umedecida em água limpa & 84,4 & 100,0 & 0,000 & 67,0 & 95,6 & 0,000 \\
\hline $\begin{array}{l}\text { Na sua percepção, em relação aos dentes } \\
\text { de leite, a opção correta é: }\end{array}$ & & & & & & \\
\hline Demais categorias & 37,5 & 6,3 & & 68,1 & 37,4 & \\
\hline $\begin{array}{l}\text { Guiam a erupção ou o "nascimento" } \\
\text { dos dentes permanentes }\end{array}$ & 62,5 & 93,7 & 0,000 & 31,9 & 62,6 & 0,615 \\
\hline $\begin{array}{l}\text { Do nascimento até a idade adulta, } \\
\text { quantas são as trocas de dentes? }\end{array}$ & & & & & & \\
\hline Demais categorias & 56,2 & 9,4 & & 50,5 & 18,7 & \\
\hline Uma & 43,8 & 90,6 & 0,013 & 49,5 & 81,3 & 0,000 \\
\hline $\begin{array}{l}\text { Em que idade começam a nascer } \\
\text { os primeiros dentes permanentes? }\end{array}$ & & & & & & \\
\hline Demais categorias & 56,3 & 12,5 & & 56,0 & 27,5 & \\
\hline De 5 a 6 anos & 43,8 & 87,5 & 0,031 & 44,0 & 72,5 & 0,082 \\
\hline $\begin{array}{l}\text { Algumas pessoas possuem dentição } \\
\text { forte devido a: }\end{array}$ & & & & & & \\
\hline Demais categorias & 17,6 & 1,1 & & 17,6 & 1,1 & \\
\hline Cuidados com a higiene bucal e alimentação & 82,4 & 98,9 & 0,000 & 82,4 & 98,9 & 0,000 \\
\hline A cárie é provocada principalmente por: & & & & & & \\
\hline Demais categorias & 59,4 & 9,4 & & 37,4 & 2,2 & \\
\hline Ingestão freqüente de produtos açucarados & 40,6 & 90,6 & 0,021 & 62,6 & 97,8 & 0,000 \\
\hline Mau hálito é causado por: & & & & & & \\
\hline Demais categorias & 21,9 & 3,1 & & 47,3 & 23,1 & \\
\hline $\begin{array}{l}\text { Falta de remoção da placa bacteriana } \\
\text { que se acumula nos dentes e na língua }\end{array}$ & 78,1 & 96,9 & 0,000 & 52,7 & 76,9 & 0,002 \\
\hline O sangramento da gengiva é: & & & & & & \\
\hline Demais categorias & 28,1 & 3,1 & & 41,8 & 13,2 & \\
\hline O primeiro sinal de uma doença gengival & 71,9 & 96,9 & 0,000 & 58,2 & 86,8 & 0,000 \\
\hline
\end{tabular}

Para evitar a inflamação da gengiva,

é preciso realizar procedimentos de

higiene bucal, utilizando corretamente:

Demais categorias

$\begin{array}{llll}59,4 & 12,5 & 78,0 & 61,5\end{array}$

Escova e fio dental

$\begin{array}{llllll}40,6 & 87,5 & 0,049 & 22,0 & 38,5 & 0,000\end{array}$

Indique a opção que pode levar o dente

a precisar de tratamento de canal:

Demais categorias

$\begin{array}{llll}9,4 & - & 17,6 & 5,5\end{array}$

Lesão de cárie não tratada

$\begin{array}{llllll}90,6 & 100,0 & 0,000 & 82,4 & 94,5 & 0,000\end{array}$

Durante a gravidez, $o$ aumento

do número de cáries se deve a:

$\begin{array}{llll}9,8 & 40,6 & 94,5 & 75,8\end{array}$

Maior consumo de produtos açucarados

$6,3 \quad 59,4 \quad 0,007 \quad 5,5 \quad 24,2 \quad 0,000$

(continua) 


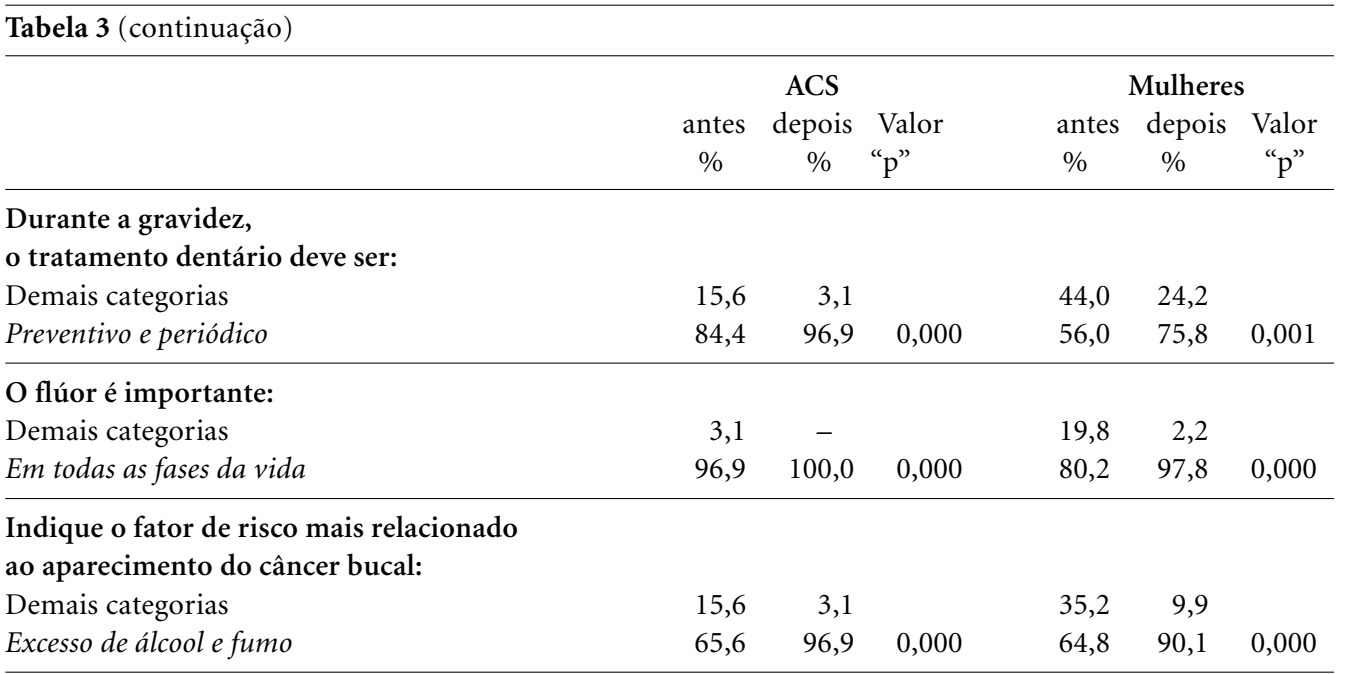

tados encontrados. O principal deles diz respeito à mudança na percepção das mulheres da área de atuação dos agentes comunitários. Ao contrário da população de ACS, da qual era esperada alguma mudança de percepção em função da participação deles em processo de capacitação, apenas modificações atribuíveis ao acaso eram esperadas na amostra de mulheres. Entretanto, passados 12 meses da capacitação dos ACS, o estudo captou significativas mudanças nos conhecimentos de saúde bucal apresentados pelas mulheres e mães, efeito que pode ser atribuído ao trabalho desse pessoal, realizado por meio de visitas domiciliares. $\mathrm{O}$ papel de tradutor, veiculando na comunidade saberes e práticas biomédicas, foi verificado em dois grupos focais de áreas distintas na cidade de Bauru-SP, envolvendo a participação de usuários e ACS (Levy et al.8).

$\mathrm{Na}$ população de estudo entrevistada, o flúor foi considerado importante para a saúde bucal. Tanto as respostas obtidas na primeira quanto na segunda observação indicaram essa percepção, um fato relevante comparado a outras populações. Resultado em direção contrária foi relatado num estudo recente em população semelhante. Unfer \& Saliba27, avaliando o conhecimento popular de 389 usuários de unidades públicas de saúde em Santa Maria-RS, na qual $80,2 \%$ eram mulheres, verificaram que a presença e os benefícios do flúor no creme dental e na água de beber não foram reconhecidos pela população estudada.

Analisando as questões separadamente, foram observadas proporções mais elevadas de respostas esperadas entre os ACS do que entre as mulheres. Além do processo de capacitação, tal resultado pode estar associado às diferenças na distribuição da renda familiar e dos níveis de escolaridade geral que caracterizavam as duas populações; entretanto, o exame dessa relação não foi propósito deste estudo.

No que pesem essas diferenças, duas questões mostraram resultados indicativos de dificuldades de assimilação pelos ACS de certos temas, e as conseqüências disso para a distribuição das percepções das mulheres. As questões tratavam de procedimentos para evitar a inflamação gengival e do efeito do consumo de produtos açucarados no aumento do número de lesões de cárie na gravidez.

Em relação ao primeiro tópico, proporção relevante das respostas das mulheres concentrou-se no uso de líquidos especiais para bochechos, um aspecto não relacionado diretamente ao problema. Misrachi \& Sáez ${ }^{28}$, pesquisando valores e crenças em saúde bucal numa amostra de mães chilenas, encontraram resultado semelhante. Dado o acesso da população aos meios de comunicação de massa, o resultado em Rio Grande da Serra pode ser indicativo de percepções produzidas pela repetição contínua e ostensiva de certas mensagens mercadológicas na mídia, que estimulam o uso de substâncias antissépticas como solução para o mau hálito e o controle da placa bacteriana. Embora esse último aspecto seja um importante fator causal implicado na inflamação gengival, sabe-se que a ação desses produtos é apenas indireta. 
Quanto ao segundo tópico, o aumento das lesões de cárie na gravidez foi considerado por parte das mulheres e mães como algo decorrente da perda de cálcio dos dentes, uma noção difundida entre profissionais de saúde com base no conceito teórico - dedutivo e não demonstrado - de que durante a gravidez ocorre um enfraquecimento dos dentes da gestante provocado pela perda de cálcio, atribuída às exigências metabólicas do embrião (Douglas 29 ). De fato, a conexão da gestação com problemas dentários é uma noção com raízes em valores e crenças populares (Misrachi \& Sáez ${ }^{28)}$. Estudos clínicos têm mostrado que os tecidos bucais são afetados pela gestação, mas não há evidência científica de que ela cause gengivite ou aumento na incidência de cáries (Laine ${ }^{30}$ ). As respostas a essas questões mostraram que certos conhecimentos encontram-se bastante enraizados no universo popular, exigindo para sua modificação esforços mais complexos do sistema de saúde.

Em duas questões na população de mulheres, ao contrário do que ocorreu na população dos ACS, não foram observadas diferenças estatisticamente significativas $(p>0,05)$. Embora a freqüência relativa à opção esperada tenha aumentado, aspecto que pode ser atribuído à atuação dos ACS, uma proporção importante não considerou que os dentes de leite eram elementos essenciais para guiar a erupção dos dentes permanentes; e, também, não indicou para a erupção dos primeiros dentes permanentes o período de 5 a 6 anos de idade. Tal resultado mostra que parte dos conhecimentos assimilados pelos ACS não foi apreendida pela população. O grau de complexidade do tema e a pouca ênfase dada nas conversas durante as visitas domiciliares, entre outros aspectos, podem representar hipóteses explicativas.
O resultado mais importante deste estudo foi a mudança na percepção das mulheres e mães observada em relação a aspectos de saúde bucal. Isto pode ser um importante indicativo do lugar que podem ocupar os ACS na promoção da saúde bucal, especialmente na superação das reconhecidas barreiras de comunicação permeadas por confronto de valores e modelos explicativos (Misrachi \& Sáez ${ }^{28}$, Moreira et al.31), mas também resultantes de relações de poder entre profissionais e usuários (Bernd et al.32). Evidências sugerem que, isoladamente, melhoria no conhecimento não se traduz em mudança de comportamento, mas ajuda as pessoas a tomar decisões informadas sobre sua saúde bucal (Gift et al.33).

Ainda que neste estudo tenha sido medido o impacto relacionado à saúde bucal de um recurso de promoção da saúde muito mais amplo, representado pelo PACS, é lícito admitir que mudanças de percepção em outras áreas e domínios de saúde estão ocorrendo e alterando o repertório de conhecimentos das pessoas, o que sugere repercussões na autoconfiança e na capacidade para controlar determinantes implicados no processo saúdedoença.

As observações documentadas no presente estudo mostraram uma dimensão do papel de agente de mudança desempenhado pelos ACS (Brasil34). Esse papel pode estar relacionado ao conjunto de alterações que estão se processando na dinâmica social que envolve a atuação deste tipo de pessoal, caracterizada por um agir que se estabelece mediante a conversa, favorecendo o estreitamento de vínculos - mediado pela confiança, responsabilidade, respeito e compromisso (Carvalho ${ }^{35}$ ) - contexto no qual a superação de antigas crenças e a assimilação de novos valores pode ser alcançada.

\section{Colaboradores}

P Frazão orientou todas as etapas da pesquisa e a elaboração do manuscrito. D Marques participou de todas as etapas da pesquisa, incluindo a análise dos resultados e a redação do trabalho, sendo responsável pelo pré-teste do formulário e pela coleta dos dados nos dois momentos.

\section{Agradecimentos}

Os autores agradecem o apoio da Secretaria Municipal de Saúde de Rio Grande da Serra, e a colaboração dos agentes comunitários de saúde e das mulheres e mães entrevistadas. 


\section{Referências}

1. Brasil. Ministério da Saúde. Fundação Nacional de Saúde. Departamento de Operações. Programa Nacional de Agentes Comunitários de Saúde. Brasília: MS; 1993.

2. Brizolara RV, Oliveira AC, Frazão P. Problemas de saúde bucal coletiva: percepções de agentes comunitários de saúde da região do $\mathrm{ABC}$, Estado de São Paulo, Brasil. Rev C S Col 2003; 8(S-2):381. [resumo]

3. Martins CL, Oliveira LSS, Rodrigues MA, Watanabe HAW, Jacomo YA. Agentes comunitários nos serviços de saúde pública: elementos para uma discussão. Saúde em Debate 1996; 51:38-43.

4. Solla JJSP, Medina MG, Dantas MBP. O PACS na Bahia: avaliação do trabalho dos agentes comunitários de saúde. Saúde em Debate 1996; 51:4-15.

5. Gonzaga AA, Müller-Neto JS. Usuários avaliam as equipes de saúde da família em Mato Grosso. Revista Brasileira de Saúde da Família 2000; 1(3):3:53-6.

6. Silva JA. O agente comunitário de saúde do Projeto Qualis: agente institucional ou agente da comunidade? [tese]. São Paulo: Faculdade de Saúde Pública da Universidade de São Paulo; 2001.

7. Nunes MO, Trad LB, Almeida BA, Homem CR, Melo MCIC. O agente comunitário de saúde: construção da identidade desse personagem híbrido e polifônico. Cad Saúde Pública 2002; 18(6):1639-46.

8. Levy FM, Matos PES, Tomita NE. Programa de agentes comunitários de saúde: a percepção de usuários e trabalhadores da saúde. Cad Saúde Pública 2004; 20 (1):197-203.

9. Costa ICC, Unfer B, Oliveira AGRC, Arcieri RM, Moraes E, Saliba NA. Investindo na promoção de saúde: PSF e PACS, uma análise de suas performances em oito municípios brasileiros. Revista da ABOPREV 1998; 1(1):30-7.

10. Trad LAB, Bastos ACS. O impacto sociocultural do Programa de Saúde da Família (PSF): uma proposta de avaliação. Cad Saúde Pública 1998; 14:429-35.

11. Kar SB, Pascual CA, Chickering KL. Empowerment of women for health promotion: a meta-analysis. Soc Sci Med 1999; 49:1431-60.

12. Wagner ABP, Wagner HL, Talbot Y, Oliveira E, Czeczko NG, Ribas CAPM, et al. Trabalhando com famílias em saúde da família. Revista Médica do Paraná. 1999; 57(1/2):40-6.

13. Vieira S, Hossne WS. Metodologia científica para a área da saúde. São Paulo: Campos; 2002.

14. Frazão P. Promovendo a saúde bucal coletiva: manual para agentes comunitários de saúde. São Bernardo do Campo: Universidade Metodista de São Paulo; 2001.

15. Bordenave JD, Pereira AM. Estratégias de ensinoaprendizagem. Petrópolis: Vozes; 1998.

16. Streiner DL, Norman GR. Health measurement scales: a practical guide to their development and use. New York: Oxford University Press; 2001.

17. Piovesan A, Temporini ER. Pesquisa exploratória: procedimento metodológico para o estudo de fatores humanos no campo da saúde pública. Rev Saúde Pública 1995; 29(4):318-25.
18. Chauí M. Convite à filosofia. São Paulo: Ática; 1997.

19. Nutbeam D. Health promotion glossary. Health Promot Int 1998; 13:349-64.

20. Richardson RJ. Pesquisa social: métodos e técnicas. 5a ed. São Paulo: Atlas; 1985.

21. Goode WJ, Hatt PK. Métodos em pesquisa social. São Paulo: Companhia Editora Nacional; 1973.

22. Pereira JCR. Análise de dados qualitativos: estratégias metodológicas para as ciências da saúde humanas e sociais. São Paulo: Edusp; 2001.

23. Lefèvre F. "Você deixaria sua filha se casar com um negro?” Algumas considerações sobre a ambigüidade nas questões de pesquisa. Saúde e Sociedade 1994; 3(2):186-96.

24. Valentini W, Levav I, Kohn R, Miranda CT, Mello AAF, Mello MF, Ramos CP. Treinamento de clínicos para o diagnóstico e tratamento da depressão. Rev Saúde Pública 2004; 38(4):522-8.

25. Flores EMTL, Drehmer TM. Conhecimentos, percepções, comportamentos e representações de saúde e doença bucal dos adolescentes de escolas públicas de dois bairros de Porto Alegre. Rev C S Col 2003; 8(3):743-52.

26. Faustini DMT, Novo NF, Cury MCFS, Juliano Y. Programa de orientação desenvolvido com adolescentes em centro de saúde: conhecimentos adquiridos sobre os temas abordados por uma equipe multidisciplinar. Rev C S Col 2003; 8(3):783-90.

27. Unfer B, Saliba O. Avaliação do conhecimento popular e práticas cotidianas em saúde bucal. Rev Saúde Pública 2000; 34(2):190-5

28. Misrachi CL, Sáez MS. Valores, creencias y practicas populares en relación a la salud oral. Cuad Méd Soc 1989; 30(2):27-33.

29. Douglas CR. Fisiologia aplicada à prática odontológica. São Paulo: Pancast; 1988.

30. Laine MA. Effect of pregnancy on periodontal and dental health. Acta Odontol Scand 2002; 60:257-64.

31. Moreira TP, Nuto SAS, Nations MK. Confrontação cultural entre cirurgiões-dentistas e a experiência de usuários de baixa renda em Fortaleza, Ceará. Saúde em Debate 2004; 28(66):58-67.

32. Bernd B, Souza CB, Lopes CB, Pires Filho FM, Lisboa IC, Curra LCD et al. Percepção popular sobre saúde bucal: o caso das gestantes do Valão. Saúde em Debate 1992; (34):33-9.

33. Gift HC, Corbin SB, Nowjack-Raymer RE. Public knowledge of prevention of dental disease. Public Health Rep 1994;109:397-404.

34. Brasil. Ministério da Saúde. Secretaria de Políticas de Saúde. Departamento da Atenção Básica. O trabalho do Agente Comunitário de Saúde. Brasília: MS; 2000.

35. Carvalho VLM. A prática do Agente Comunitário de Saúde: um estudo sobre sua dinâmica social no município de Itapecerica da Serra [dissertação]. São Paulo: Faculdade de Saúde Pública da Universidade de São Paulo; 2002.

Artigo presentado em 27/06/2005

Aprovado em 3/09/2005

Versão final apresentada em 1/10/2005 